\title{
Digital Inclusion Of Ict And Its Implication Among Entrepreneurs Of Small And Medium Enterprises
}

\author{
Faradillah Iqmar Omar, Nur Ajeerah Othman, Nor Azlili Hassan
}

\begin{abstract}
The emergence of new digital technologies and the existence of digital media has had an important impact in changing the operation of business environment. Correspondingly, the diversity of applications and digital media has now provided a broader space for the users, including the entrepreneurs, to enhance and upsurge their contact with customers and suppliers in entrepreneurship sector. Information and Communication Technology (ICT) and the Web are particularly the integrated and dynamic tool in nurturing entrepreneurship as well as act as the communication and marketing tool to grow the business. It is important to explore the new phenomenon in entrepreneurship that is closely related to ICT usage. The purpose of this study was to identify the patterns of ICT usage and to analyze the relationship between digital inclusion and its implications among entrepreneurs of small and medium enterprises (SMEs). The quantitative method is employed in this study with samples aimed at focusing on entrepreneurs in the Klang Valley. A questionnaire was distributed directly to 500 respondents aged between 18 to 55 years old. The data collected were analyzed descriptively and with correlation inference by using the SPSS software. The finding indicated a significant and strong relationship between digital inclusion and its implications ( $p<0.005, r=.685)$ among entrepreneurs of SMEs. It revealed that the entrepreneurs with high involvement in ICT usage have high implications in terms of innovation and business satisfaction. The study recommends that the government should play a dynamic role in education and training for the development of the SMEs as well as bridge the gap among the SMEs to adopt the use of digital media tools. In sum, the use of ICT contributes to enhance a number of benefits such as to be more competitive, innovative, expanding business networks and gaining more global marketing opportunities.
\end{abstract}

Index Terms: Digital Inclusion, Digital Media, Implications, Entrepreneurs, Entrepreneurs of SMEs

\section{INTRODUCTION}

The existence of today's online entrepreneurs is very encouraging. This phenomenon is an important part of the economic catalyst in the era of the Industrial Revolution 4.0. One of the elements in creating digital entrepreneurs is by looking at the aspects of digital inclusion and their

Revised Manuscript Received on April 19, 2019.

Faradillah Iqmar Omar, Senior Lecturer, Faculty of Management and

Mualamah, Kolej Universiti Islam Antarabangsa Selangor (KUIS) (email: faradillah@kuis.edu.my)

Nur Ajeerah Othman, Postgraduate, Faculty of Social Sciences and Humanities, Universiti Kebangsaan Malaysia (UKM)

(email: jeeraothman@gmail.com)

Nor Azlili Hassan, Senior Lecturer, Faculty of Creative Industry, Universiti Tunku Abdul Rahman (UTAR)

(email: azlili@utar.edu.my) implications in entrepreneurship. Information and Communication Technology (ICT) is believed to have the ability to be the best entrepreneurship platform ever today if it is fully utilized. The emergence of ICT has influenced many industries and businesses including entrepreneurship. The economy in Malaysia has been transformed from a nation of product-based production to a producer of industrial products and lately as a knowledge based economy. Hence, the government is placing greater stress on the effect of ICT.

ICT is also the important means that offers the prospect for small and medium enterprises (SMEs) in improving their effectiveness in entrepreneurship field. In this swiftly changing commercial situation of the 21 st century, it is tremendously vital for SMEs to embrace ICT knowledge to preserve their competitive authority, create a global network of product trade and create a broader international system. The efficient usage of information system (IS) and information technology (IT) can proposition SMEs with the chance to take benefit of ICT to develop the method they operate business and improve the key capabilities. The SMEs segment is lately of great significance to the Malaysian economy as it has been documented as the pillar of the economy and performed a substantial role in creating employment, improving the quality of human resources, fostering an entrepreneurship culture, encouraging the big industries and launching new entrepreneurship prospects. Being operated with minor capital prerequisite, SMEs is always considered as a stage for young and ambitious entrepreneurs to start off their enterprises.

SMEs has been allotted numerous information and communication technologies funds through many government programs to aid them to adopt with information technology. In fact, ICT is considered as a tool to raise the competitive level of SMEs in entrepreneurship arena. However, SMEs in Malaysia is still remaining on the incorrect side of a digital gap (Karkoviata, 2001). In this situation, the inclusion and use of ICT is broadly seen as vital for the effectiveness of SMEs in the emergence of a global market. Given this phenomenon, this study pursues to explain the scenario through a survey of SMEs in Malaysia. Hence, the study will descriptively review the digital inclusion of entrepreneurs and their implications in the 
entrepreneurship. The purpose of the study are to recognize the patterns of ICT usage and to investigate the relationship between digital inclusion and its implications among entrepreneurs of small and medium enterprises (SMEs). This article discusses the implications of digital inclusion among entrepreneurs, from aspects of innovation, business management and satisfaction gained by the SMEs entrepreneurs. Hence, it is important to see the relationship between digital inclusion and its implications in the entrepreneurship. This can empower and allow the future ICT usage in managing the entrepreneurship in line with the era of Industrial Revolution (IR) 4.0.

\section{LITERATURE REVIEW}

A. ICT and Entrepreneurs in 4th Industrial Revolution (IR 4.0)

Industrial evolution process began with the first industrial revolution which was implemented in the 18th century (1750) until 19th century that focused on the iron and textile industries, together with the growth of steam engine that performed a significant role in the first Industrial Revolution (IR 1). Following the first industrial revolution is the development of technology during the second (2nd) industrial revolution between the year 1870 and 1980 which is evolving on steel, oil and electric as well as electric power in creating the mass production. Major revolution can be seen through the technological innovative that allowed the existence of telegraph, telephone, light bulb, phonograph and the internal combustion engine. The advancement of technology made another step into the third (3rd) industrial revolution or be recognized as the Digital Revolution in the year 1980 where the evolution of technology is created from the analog electronic and mechanical devices toward the digital technology. As such, technology can be seen in the emergence of personal computer, as well as the internet ICT (Zhao Hao Sun, 2018).

According to Zhao Hao Sun (2018), the evolution of technology does not seem to stop only at the 3rd industrial revolution. Apparently, it has now reached the fourth (4th) industrial revolution. The development of technology has been recognized as industrial revolution 4.0 which is the name applicable for the present trend of mechanization and data exchange in manufacturing technologies which involves cyber - physical systems, the Internet of Things (IoTs), cloud computing and cognitive computing. The technology has innovations in several fields including artificial intelligence, nanotechnology, quantum computing, biotechnology, IoTs, 3D printing, big data and big data analytics. Professor Klaus Schwab, the founder and executive chairman of the World Economic Forum invented the term 4th Industrial revolution in his book entitled The Fourth Industrial Revolution which stated that the IR 4.0 is essentially different from the prior IRs, which were described mainly by the advances in technologies. According to Klaus, the technology is potential to connect billions of people to the web such as Facebook and the Internet of things, and may radically advance the productivity of business and organizations like big data analytics and artificial intelligence, thus the human working and life also regenerate the natural environment (Zhao Hao Sun, 2018).

Entrepreneurship and 4th industrial revolution can be comprehended through the innovation and technology advancement that being applied by the entrepreneurs as part of the new wave of industrial revolution. Innovation is often regarded as the use for a better resolutions that facilitate new necessities, unstated needs or prevailing market demands (Maryville 1992; Zhao Hao Sun 2018). Hence, the inclusion of the new technology and taking advantages of the ICT are among the crucial impacts that entrepreneurs should not take for granted because it will be the catalyst for their continuous development and become more competitive, either in domestic or international markets.

The demand of the market is currently in line with the requirements of technology, thus make the ICT usages in entrepreneurship as the most significant aspect to be learned and applied in the entrepreneurship. This argument was supported by a research done by Universiti Putra Malaysia (UPM) which focused on the benefits of ICT for Youth Agro-based Entrepreneurs in Malaysia. The research stated through ICT, the entrepreneurs can expand their operative efficiency, simultaneously boost their revenue, fortify their selling aspects as well as create the different prospects by penetrating into the global market (Siti Aisyah Ramli et al., 2015). The growth in the operational efficiency can be found through the perspectives of many sectors which have benefited from the usage of ICT in their respective fields especially when the fields involved the improvement responses from the customers and increase the productivity of the entrepreneurship process (Harindranath et al., 2008; Omar et al., 2014; Ghee-Thean et al., 2012, Siti Aisyah Ramli et al., 2015).

Apparently, the inclusion of ICT in entrepreneurship may reduce both direct and indirect cost, especially for the marketing purposes such as the cost of advertisement to promote their services or products. Similarly, the ICT inclusion can also improve their business processes. The reducing cost at certain production stages helps the entrepreneurs to save their money and increase their incomes (Siti Aisyah Ramli et al., 2015). Furthermore, ICT inclusion help the entrepreneurs to access the up-to-date market information and aware on the current trends of the consumers. Hence, this opportunities has offered more advantages to the entrepreneurs to enhance their marketing features at both local and international stage (Bahaman et al., 2009; Siti Aisyah Ramli et al., 2015).

According to the research team from UPM, the ICT gives new opportunities for the entrepreneurs to penetrate into the global market. Similarly, the entrepreneurs are able to find new business partners to collaborate, exchange information, reach new potential customers and expand to new markets, as well as to improve the network coordination (Zhue et al., 2006; Siti Aisyah Ramli et al., 2015). By stepping into global market, may eventually make the entrepreneurs to be more prepared with the technological knowledge as their products or services that beyond the borders and other 
countries as well. Hence, it is significant to have knowledge on technology and usage of ICT as part of their entrepreneurship process.

\section{B. Digital Inclusion}

Digital inclusion by the entrepreneurs can be comprehended through the events of ICT usage as part of the entrepreneurship activities. The early stage of digital inclusion among the SMEs entrepreneurs in Malaysia started when the Malaysian government gave prominence towards the enhancement of ICT knowledge among the society to keep up with the global communication technology (Siti Aisyah Ramli et al., 2015). Besides, digital inclusion can be recognized as the advancement of technology where the entrepreneurs mobilized the software system and digitization to the innovation of the amalgamations of technologies that empowering the firms to revolutionize their entrepreneurship models, involving the production and engineering services. The revolution is prospective to enhance the economic development and the quality of life. Moreover, it will certainly lead to the creation of new job opportunities as well as social and product innovation (Min Hwa Lee et al., 2018).

The development of ICT has become the fundamental for many working process and can be performed easily and efficiently. ICT has make life possible for many difficult tasks that involve expertise in certain fields and complete the tasks without having mistakes. Fanny Adams et al. (2016) found that the actual disposition of digital technologies for business enterprise in Sub-Sahara Africa are dependent on the internet usage and aware on the importance of internet for their entrepreneurship (Voseenberg, 2013). Similarly, Roth, Kaivo-Oja and Hisrshmanc (2013) has discovered that access to the internet promotes the growth of inventive capacity amongst entrepreneurs in the trades industry. Hence, digital inclusion in the entrepreneurship occurs with the involvement of technology in the daily activities among the entrepreneurs.

Furthermore, there is also a study that done on the factors influencing acceptance and ICT usage for business functions among 140 women-owned SMEs in Nigeria. Erumi-Esin and Heeks (2015) found that the advancement of technology brought new environment into the business society including the e-business technologies that become the potential entrepreneurs (Fanny Adams et al., 2016). The study has been conducted in several countries and shown that the digital inclusion can be seen as means of enhancing entrepreneurial activities through the ICT usage. As a supplementary to ICT usage, the entrepreneurs must ensure that they took advantages of internet to assists them in marketing activities. This is supported by Fanny Adams et al. (2016) which stated that the internet has been incorporated into the entrepreneurial life and this can be seen in various kinds of activities that involving entrepreneurs to be online.

Entrepreneurs have contributed an important role in the entrepreneurship sector and the country's economic development. Nowadays, entrepreneurs are partly engaged in online business by using various e-commerce platforms.

\section{Entrepreneurs and ICT}

While entrepreneurs are highlighted as having an important contribution towards the country, however, studies on digital entrepreneurship are still lacking. Ironically, the ICT usage, particularly the internet is closely linked to socio-economic developments and this has the potential for individual and social transformation. This is in line with Lee (2004) who mentioned that ICT is a tool that can be used to develop entrepreneurship in the future. In fact, the usage of the Internet and ICT have also been identified as the factors for individual and societal empowerment (Lee 2004; Maeir \& Nair-Reichert 2007; Choudry 2009; Wamala 2012, UNCTAD 2014). Move over, according to Joseph (2013), ICT plays an important role in providing opportunities for the women development and empowerment. In addition, reports from the OECD (2013) stated that the empowerment of economies depends on the rights, access and decisionmaking capabilities of their property and assets.

Ironically, ICT offered new opportunities for the entrepreneurs to start and grow businesses. Through a new ICT forms, entrepreneurs can reach their customers, become more efficient and generate their businesses better than traditional settings (UNCTAD, 2014). Similarly, the usage of digital technology aims to improve the societal life either through direct or indirect participation. The emergence of new digital technologies and the existence of digital media had an important impact on communication change (Okoro 2012). The diversity of applications and digital media provides more spaces for the users to employ technology in various aspects of life including entrepreneurship. Accordingly, Sinkovics et al. (2004) found that ICT and the Web are particularly the integrated and dynamic tool in nurturing entrepreneurship. Additionally, the usage of ICT applications including e-mail, internet and video conferencing may enhance the understanding and knowledge about the international market. In fact, ICT offers a number of benefits such as expanding global business networking and gaining more global marketing opportunities. However, the UNCTAD (2014) reported that the entrepreneurs may be less aware of ICT applications, or less access to ICT usage training tools. They also have no access to required resources such as finance and expertise, in order to invest and learn how to use these tools effectively. Hence, it is important that this study explains how digital inclusion takes place among the entrepreneurs.

Wanyoike et al. (2012) notes that the development of this business world is based on the decisions made by the entrepreneurs who want to make changes in the business environment. One of these changes is the ICT revolution that includes opportunities and threats to small businesses. Hence, it is evident that businesses have become more evolving with the transformation of ICT as one of the catalysts for the developments and changes. The term 'Digital Entrepreneurship' often implies the process of establishing an internet-based business, products or services. This explanation is not only covers the starting point and brings new digital products or services to the market but also the digital conversion of existing business activities 
within a firm or public sector (Van Welsum, 2016). In that regard, digital entrepreneurship must be considered as technological developments and infrastructure advancements which generate prospects for the entrepreneurs. Hence, digital inclusion among entrepreneurs is an important indicator that needs to be refined in developing a new digital entrepreneurial model as previous research focuses only on entrepreneurial technical aspects of challenges, problems, structures, management, leadership and success. The situation should be seen from the aspect of digital entrepreneurship itself by using ICT.

According to Shropshire Council (2016), there are some key elements in the measurement of digital inclusion; namely i) tools to access the internet, ii) the ability to use the internet effectively, iii) motivation to use internet surfing tools and skills. These three elements are the important factors in accessing an affective internet. This will be identified in the development of the digital entrepreneurial phenomenon that arises out of technology assets such as the internet as well as information and communications technology (Le Dinh et al., 2018). In general, any entrepreneurial endeavor that shifts the assets, services or most businesses into digital can be characterized as digital entrepreneurship. According to Hull et al. (2007), digital entrepreneurs have many differences over the non-digital entrepreneurs such as products, marketing and workplace activities. Digital entrepreneurship has great impact around the world, particularly in the last decade. Google, Facebook, Microsoft and Apple have not only revolutionized the business world but also designed the way individuals connect with each other in daily life. Today, we live in a digital world, where artificial intelligence can be utilized to improve the quality of our decisions and perceptions about reality and can be enhanced to broaden our perspectives in various situations. Digital world is not only make the computing, storing and researching information easier, but also more flexible and economical when services are constantly changing and the internet changes in the direction of a so-called the Internet of Things (IoTs). By 2020, IoTs technology is anticipated to be executed in 95 percent of electronics with the new product designs (Richter, Kraus and Bouncken, 2015; Panetta, 2017).

\section{Framework}

\begin{tabular}{|c|c|}
\hline $\begin{array}{l}\text { Digital Inclusion of ICT } \\
\text { Domain } \\
\text { - Social Networks } \\
\text { - Information Seeking } \\
\text { - E-commerce } \\
\text { - Marketing }\end{array}$ & $\begin{array}{l}\text { Implications of Digital } \\
\quad \text { Inclusion } \\
\text { - Entrepreneurial Innovation } \\
\text { - Technological Innovation } \\
\text { - Management } \\
\text { - Business Satisfaction }\end{array}$ \\
\hline
\end{tabular}

Fig 1. Framework of Digital Inclusion and Its Implication

\section{METHODOLOGY}

This study employs a survey method with sets of questionnaires distributed to the respondents. A total of 500 entrepreneurs of 18 and 55 years old were participated as the unit of analysis. Entrepreneurs who are participated as the sample in this study must meet the criteria set by the researcher; have a registered business in the Klang Valley model. Accordingly, digital entrepreneurship is a

(Bangi, Kuala Lumpur, Shah Alam). Generally, these entrepreneurs are comprised of Small and Medium Enterprises (SMEs) from various sectors. The researchers also find the information related entrepreneurs with SME Corp. Once the set of questionnaires is completed, the researchers do the pre-test among the 30 respondents to ensure the validity and reliability of the items in the questionnaire before going to the field work. All items are tested with Cronbach's Alpha above 0.7 and if there are found the weaknesses, the items will be changed and corrected for data collection in the fieldwork.

\section{FINDINGS AND ANALYSIS}

\section{A. Demographic Data}

Table 1 shows the demographic information of all the respondents. With total respondents of 500, majority of the respondents came from age group 28 to 37 years old (39\%), followed by age group 18 to 27 years old (25\%), age group 38 to 47 years old (22\%), age group 48 to 57 years old (10\%) and only 9 participant is aged above 58 years. Age of the respondent is one of the significant characteristics that determined the participation of entrepreneurs in SMEs. This is because the age group will determine their maturity on setting their own business and able to understand the risk that they will face when they own the business. Thus, it indicated that this age group already reach their maturity and able to measure the situation they will face once starting their own business. Meanwhile, the age group of 58 years old and above is reflected the idea that the respondent at this age group is entrusting the business to their successor.

Furthermore, with regards on ethnicity, it was found that the Malays are the highest ethnic group who participated as the SMEs entrepreneurs $(88 \%)$. The other ethnic groups such as Chinese (8\%), Indian (3\%) and Bumiputera Sabah $(1 \%)$ are the minority ethnic groups who have business in SMEs. Hence, it shows that Malays are the majority who owned business in SMEs. $66.4 \%$ of the respondents were married and $30.4 \%$ were single, whereas about $2.2 \%$ of the respondents were among the single mothers and only $1 \%$ of the respondents were the widows. This findings revealed that the marital status does not determine the participation of the respondents as SMEs entrepreneurs. Being married and having a family are not the obstacles for the respondent to become an entrepreneur.

The majority of the respondents are males that contributed $58 \%$ of the total respondents while the females are only contributed $42 \%$ with 210 respondents. The majority of the respondents were SPM holders, with 160 respondents (32\%). 150 respondents were having STPM/certificate/diploma $(30 \%)$ while Undergraduates has received $27 \%$ of the total respondents, which is equal to 135 respondents. Education level is one of the most important characteristics that have affected the participation of the respondents as the SMEs entrepreneurs. There is large number of respondents who were educated and believed that it is important for the entrepreneurs to have educational qualifications. 
Table 1: Demographic Information of sample ( $N=\mathbf{5 0 0})$

\begin{tabular}{|c|c|c|}
\hline Items & Information & $\%$ \\
\hline \multirow{2}{*}{ Gender } & Male & 58 \\
\hline & Female & 42 \\
\hline \multirow{5}{*}{ Age } & $18-27$ years old & 25 \\
\hline & $28-37$ years old & 39 \\
\hline & $38-47$ years old & 22 \\
\hline & $48-57$ years old & 10 \\
\hline & 58 years old and above & 4 \\
\hline \multirow{4}{*}{ Ethnic } & Malay & 88 \\
\hline & Chinese & 8 \\
\hline & Indian & 3 \\
\hline & Bumiputra (Sabah) & 1 \\
\hline \multirow{4}{*}{ Marital Status } & Single & 30.4 \\
\hline & Married & 66.4 \\
\hline & Widow & 1 \\
\hline & Single Mother & 2.2 \\
\hline \multirow{7}{*}{ Level of Education } & UPSR & 1 \\
\hline & SRP/PMR & 2 \\
\hline & SPM & 32 \\
\hline & STPM/Certificate/Diploma & 30 \\
\hline & Undergraduate & 27 \\
\hline & Master & 7 \\
\hline & $\mathrm{PhD}$ & 1 \\
\hline \multirow{4}{*}{ Previous Occupation } & Government Servant & 11 \\
\hline & Private Servant & 53 \\
\hline & Unemployed & 24 \\
\hline & Others & 12 \\
\hline
\end{tabular}

The previous occupations one of the significant characteristics that determined the involvement of the respondents in SMEs. Majority of the respondents were employed as private servants (53\%) and $24 \%$ of the respondents were previously unemployed. Less satisfaction in their respective fields of occupation may become the reasons for the respondents to start their own business. SMEs created job opportunity for those who are unemployed. There were only $11 \%$ of the respondents from the government sectors who have left their job to be an entrepreneur.

\section{B. Correlation}

H1: There is a significant relationship between digital inclusion domain and the implications of digital inclusion.

Based on the findings of the correlation analysis, the study found that the relationship between digital inclusion domain and its implication was a modest but positively significant relationship $(\mathrm{r}=.599, \mathrm{p}<0.05)$. This decision explains that the entrepreneurs with high involvement in ICT usage have high implications in terms of innovation and business satisfaction. This explains that with a high level of digital inclusion, there will have a high implication in the business of entrepreneurs. Thus, the hypothesis is accepted. Table 1 shows the correlation of the analysis.

Table 2. Relationship between Digital Inclusion and Implications

\begin{tabular}{|c|c|c|c|}
\hline & & $\begin{array}{l}\text { Digital } \\
\text { Inclusion }\end{array}$ & Implieations \\
\hline \multirow{3}{*}{$\begin{array}{l}\text { Digital } \\
\text { Inclusion }\end{array}$} & Pearson & \multirow{2}{*}{1} & $599 * *$ \\
\hline & Correlation & & 000 \\
\hline & $\begin{array}{l}\text { Sig. (2-tailed }) \\
\mathrm{N}\end{array}$ & 500 & 500 \\
\hline \multirow{2}{*}{$\begin{array}{l}\text { Implicati } \\
\text { ons }\end{array}$} & $\begin{array}{l}\text { Pearson } \\
\text { Correlation }\end{array}$ & $\begin{array}{l}.588 * * \\
.000\end{array}$ & 1 \\
\hline & $\begin{array}{l}\text { Sig. (2-tailed) } \\
\mathrm{N}\end{array}$ & 500 & 500 \\
\hline
\end{tabular}

\section{CONCLUSION}

Information Communication and Technology is discovered to play a critical role for any organization involving entrepreneurship. The use of ICT that vary from processor to personal computers and from word processing to sophisticated application. The systems of ICT also can offer a variety of advantages to different users. The purpose of this research is therefore, to identify the patterns of ICT usage and to analyze the relationship between digital inclusion and its implications among entrepreneurs of small and medium enterprises (SMEs).

This study investigated the use of ICT among the entrepreneurs in SMEs. Understanding the entrepreneur's attitudes and behavior on ICT is very important in order to improve their services by utilizing these tools for marketing the products and services as well as fulfilling these requirements. The findings suggested that the mass of entrepreneurs were using ICT, respectively. There was a positive and significant relationship between digital inclusion and its implications among the entrepreneurs of SMEs. Entrepreneurs added to the substance of social networking web sites through posting their products and services. The entrepreneurs who used the ICT will become more competitive, innovative and even can expand their business networks globally and gain more global marketing opportunities as well.

The findings are anticipated to add to a better awareness of the issues that promote ICT practice among the SMEs. It is imperative to have more practical proof of the elements affecting the acceptance of ICT to help managers, governing bodies and ICT suppliers further access the advantages of its constant and potential growth. In addition, these study also useful as a basis for future research of SMEs in Malaysia. The policy makers such as government should perform a critical role in education and training in a knowledge society. They should offer training through universal education courses and lifetime learning and offer the essential info and communication technology abilities for all entrepreneurs to develop their knowledge to deal with these new technologies. Further inquiry is necessary to gain a clearer insight of the utilization of ICT by entrepreneurs in the SMEs. Other segments of the populace should also be examined to produce a bigger and clearer picture on the subject matter. It is also valuable to study other personal attributes, particularly the relationship between various social networking instruments with age groups, language proficiency, and level of computer and internet familiarity.

\section{ACKNOWLEDGMENT}

The research is funded through the project FRGS/1/2016/SS09/KUIS/03/1 of the Fundamental Research Grant Scheme (FRGS) from the Ministry of Higher Education. 


\section{REFERENCES}

1. Erumi-Esin, R., \& Heeks, R. (2015). E-business adoption and use among African women-owned SMEs: an analytical study in Nigeria. In Proceedings of the Seventh International Conference on Information and Communication Technologies and Development (p. 11). ACM.

2. Ghee-Thean, L., Abd, Latif, I. \& Hussein, M. A. (2012). Does technology and other determinants effect fishing efficiency? An application of stochastic frontier and data envelopment analyses on trawl fishery. Journal of Applied Science 12: 48 - 55.

3. Harindranath, G., Dyerson, R. \& Barnes, D. (2008). ICT adoption and use in UK SMEs: A failure of initiatives? Electron Journal Information System Evaluation 11: 91 96.

4. Juvonen, P. \& Ovaska. P. (2012). ICT Entrepreneurship model: A new approach for information technology bachelor education. 14th IFAC Workshop on International Stability and Systems Engineering45 (10).

5. Karkoviata, L. (2001). SMEs reluctant to go online. Asian Business 37(4): 75-76.

6. Maryville, S. (1992). Entrepreneurship in the business curriculum. Journal of Education for Business 68(1): 27 -31 .

7. Nemer, D. (2015). From digital divide to digital inclusion and beyond: A positional review. The

8. Journal of Community Informatics 11(1).

9. Omar, S. Z., Osman, N., Bolong, J., D'silva, J. L. \& Shaffril. H. A. M. (2014). Individual factors on readiness of youth fishermen in Malaysia to use Global positioning systems. Journal of Applied Sciences 14: 2628 - 2631.

10. Quagrainie, F. A. \& Ariwa, E. (2016). Effective Deployment of Digital Technologies for Business Enterprise in Sub-Sahara Africa: Applications for Women Entrepreneurs e-readiness for internet usage in Ghana. The Sixth International Conference on Innovative Computing Technology

11. Ramli, S. A., Samah, B. A., Hassan, M. S., Omar, S. Z., Bolong J. \& Shaffri, H. A. M. (2015).

12. Potential benefits of ICT for youth agro-based entrepreneurs in Malaysia. Journal of Applied Sciences 15 (3): $411-414$.

13. Sun, Z. H. (2018). Innovation and Entrepreneurship in the 4th Industrial Revolution. Joint Workshop on Entrepreneurship, Lae, PNG, 18 July 2018.

14. Velmurugan, M. S. \& Velmurugan, M. S. (2014). Consumer's awareness, perceived ease of use toward information technology adoption in 3G mobile phone's usages in India. Asian Journal Market 8:1 - 23.

15. Zhu, K., Kraemer, K. L., Gurbaxani, V. \& Xu, S. X. (2006). Migration to open-standard inter organizational systems: Network effects, switching costs and path dependency. MIS Q 30: 515 - 539. 